\title{
La formación de una política social: el caso del Programa de Renovación Habitacional Popular en la ciudad de México
}

\author{
Emilio Duhau*
}

El Programa de Renovación Habitacional Popular constituye la respuesta de mayor envergadura dada por el gobierno mexicano a la problemática habitacional resultante de los sismos de septiembre de 1985. En este artículo se formula una caracterización de esta respuesta, en términos de las definiciones y supuestos gubernamentales, los aparatos estatales y los actores sociales concurrentes en su realización.

Se presenta un conjunto de datos básicos sobre el programa y se proporciona una interpretación del modo en que fueron resueltas las cuestiones básicas a las que debió darse respuesta a fin de concretarlo.

A modo de conclusión se desarrollan algunas reflexiones sobre los efectos sociales previsibles, cuestionándose la visión de que la definición de un régimen de propiedad privada plena para las viviendas financiadas mediante el programa dará lugar a un proceso de especulación inmobiliaria que operará en detrimento de las familias beneficiarias.

El programa gubernamental de reconstrucción de viviendas actualmente en ejecución en el área central de la ciudad de México, iniciado por el gobierno federal con el decreto de expropiación de predios publicado el 11 de octubre de 1985, presenta un conjunto de características específicas y en alguna medida novedosas; éstas deben ser analizadas considerando el conjunto de circunstancias coyunturales emergentes del sismo de septiembre y la interacción de los diferentes actores colectivos, órganos estatales, intereses y demandas presentes específicamente en la definición de la política de reconstrucción.

Nos̀ proponemos aquí analizar el programa de reconstrucción habitacional como política social, es decir, como conjunto de acciones gubernamentales orientadas a la cobertura de necesidades de la población a través de mecanismos que sustituyen total o parcialmente los mecanismos del mercado. ${ }^{1}$ El que hablemos de "necesidades" no implica, vale aclararlo desde el principio, ninguna afirmación acerca de la orientación de la política objeto de análisis, ni una definición apriorística acerca de en qué medida "beneficia" a un determinado sector de la población.

Las políticas estatales y en particular aquellas que implican irmova-

* Departamento de sociología de la UAM-Azcapotzalco.

${ }^{1}$ Ciertos desarrollos teóricos recientes sobre política social, tienden a adoptar explicaciones de carácter funcional (Gough, 1979 y Offe, 1984), que no compartimos. Provisionalmente hemos adoptado esta definición que evita las connotaciones de tipo funcional. 
ciones en la política social, no pueden ser interpretadas sólo como el resultado de una estrategia racional dentro de la cual estén previstos todos los efectos resultantes; por ello, los desarrollos e innovaciones de la política social del Estado no pueden ser concebidos como la causa de condiciones o cambios sociales concretos, sino sólo como el iniciador de interacciones conflictivas cuyo resultado es abierto y ambivalente.

Así, el análisis de un programa como el de reconstrucción debe apuntar a la consideración de sus efectos sociales procurando responder a preguntas como las siguientes: ¿qué beneficios inmediatos, costos y perspectivas económicas son generados por un nuevo programa de política social?, ¿qué categorías de "personas afectas" son colocadas en relaciones de competencia o cooperación por el programa?, ¿en qué medida aquellos que son afectados pueden realmente exigir determinados beneficios, oponerse u obstruir regulaciones que les resultan desventajosas?, ¿hacia quiénes puede trasladar las cargas específicas resultantes un determinado grupo afectado?, ¿qué grupo de poder tiene la posibilidad de bloquear la ejecución administrativa del programa? (Offe, 1984: 106-108).

El Programa de Renovación Habitacional Popular (PRHP) está, por definición, limitado temporalmente, pero no así sus efectos ni los actores colectivos y grupos sociales involucrados. Dado que actualmente (noviembre de 1986) nos encontramos a poco más de un año de iniciada la formación del programa y que, por consiguiente, sus efectos sociales están cuando mucho insinuados, en el presente trabajo el eje de exposición estará dado, más que por una evaluación de los resultados desde la perspectiva de la población "beneficiaria", por la especificación de los procesos presentes en su formación, considerando el marco institucional definido, los grupos sociales y actores colectivos involucrados, y las demandas e intereses en juego.

\section{Los damnificados y la definición gubernamental del PRHP}

En términos del problema que aquí nos ocupa - la formación de la política social de reconstrucción habitacional en el área central de la ciudad de México - , un efecto fundamental del sismo de septiembre de 1985 fue la constitución de los "damnificados" en un actor colectivo con presencia significativa en la formación de la política de reconstrucción.

En ciertas áreas, el movimiento de damnificados se originó en las iniciativas de organizaciones preexistentes. Así ocurrió en colonias como la Morelos y Tepito (UPICM-PM, 1986). En la mayoría de los casos, en cambio, prácticamente no existían antecedentes de organización vecinal que hubieran trascendido el nivel de las vecindades aisladas. Tal fue el caso del "centro"' (área aproximadamente coincidente con el llamado "primer cuadro"), donde la Unión Popular Nueva Tenochtitlan conformó una de 
las organizaciones más grandes entre las que integran el órgano coordinador de las organizaciones independientes de damnificados, la Coordinadora Única de Damnificados (CUD) (Duhau, 1986).

Una condición fundamental en la formación del movimiento de damnificados fue sin duda la gran difusión de la vivienda multifamiliar de "renta congelada ${ }^{2}$ o muy baja, la "vecindad" en el área central de la ciudad. Más de 31\% de todo el inquilinato en el Distrito Federal se concentraba en las delegaciones Cuauhtémoc y Venustiano Carranza y, de este porcentaje, la mayor parte corresponde a la antigua "herradura de tugurios"3 en torno al centro histórico (Connolly, 1985: 39).

La incertidumbre con respecto a las viviendas afectadas, en diferentes grados, por el sismo fue un motivo fundamental de la movilización vecinal. El tema de los inquilinos que se resistían a abandonar su vivienda y de los "casatenientes" que promovían acciones destinadas al desalojo de los inmuebles se convirtió durante los días precedentes al decreto expropiatorio, en objeto destacado de la crónica periodística y de las demandas de los damnificados. Como se ha señalado reiteradamente, en muchos casos lo amenazado no era solamente la vivienda, sino también las fuentes de trabajo organizadas, en una proporción significativa, en la propia vivienda o en función de su localización.

De este modo, la solución individual del problema se presentaba, ante la población afectada, como virtualmente imposible. Las experiencias previas respecto al modo de operar de los mecanismos administrativos y judiciales permitían suponer que el afrontar la situación vecindad por vecindad y en un terreno que se percibía como favorable a los propietarios, terminaría muy probablemente con la expulsión de los inquilinos.

La solicitud de expropiación de los inmuebles afectados se presentó en este contexto como una medida que, si en sí misma no constituía una solución al problema habitacional, poseía la cualidad de bloquear las maniobras de expulsión puestas en marcha por los propietarios. Su conversión en una consigna apoyada masivamente se produjo a un ritmo semejante a la articulación de las organizaciones de damnificados. En efecto, si por una parte muchas "uniones" de vecinos se constituyeron hacia fines del mes de octubre, ${ }^{4}$ ya el 2 de septiembre, los representantes de varias organizaciones entregaron al Presidente de la República un pliego petitorio en el que se incluía, entre otras demandas, la de expropiar edificios y vecindades (Azuela, 1986: 3).

Más allá del grado en que puede haber influido la movilización de

${ }^{2}$ Entre 1942 y 1948 se expidieron varios decretos de congelación de rentas que dieron origen a las viviendas conocidas actualmente como de renta congelada.

${ }^{3}$ Denominación que se dio al área de viviendas deterioradas en torno al centro histórico (véase Coulomb, 1983).

${ }^{4}$ Los testimonios recogidos son coincidentes en cuanto a que la mayoría de las uniones de vecinos se constituyeron hacia fines del mes de septiembre. 
los damnificados en la decisión presidencial, lo cierto es que había rebasado ampliamente los mecanismos habituales de control político y resultó incorporada como un elemento fundamental en la definición gubernamental de la situación. Hacia fines del mes de octubre de 1985, establecidas ya las imstancias y aparatos a través de los cuales el Estado atendería la problemática habitacional emergente, la definición gubernamental del universo de los damnificados, expresada a través de un informe de la Comisión Metropolitana de Emergencia (CME), distinguía tres grupos de damnificados que serían atendidos a través de otros tantos mecanismos estatales:

1. Damnificados que habían perdido su vivienda que se encontraba localizada en grandes conjuntos habitacionales, como era el caso de las unidades Nonoalco-Tlatelolco y multifamiliar Benito Juárez, mismos que se encontraban administrados por entidades de carácter público.

2. Damnificados cuyas viviendas se encontraban en las colonias populares del centro de la ciudad y que fueron afectados por el sismo, identificándose entre viviendas o casas de construcción antigua donde habitaban varias familias.

3. Damnificados de colonias habitadas por personas de clase media cuyos inmuebles eran propiedad de quienes los habitaban o bien se encontraban arrendados por inquilinos (CME, 1985).

Esta delimitación de los distintos grupos de damnificados correspondió con un tratamiento diferente para cada uno, que resultó independiente en cierta medida de la condición social de las familias damnificadas e incluso, en ciertos casos, de las relaciones sociales establecidas en torno a la ocupación de la vivienda. ${ }^{5}$

La problemática habitacional en el área central y las rectificaciones al decreto de expropiación de inmuebles

La expropiación de predios urbanos en la ciudad de México tiene importantes antecedentes como instrumento de política urbana (Ziccardi, 1986: 64 y Azuela, 1986: 2). También la definición estatal del tema del deterioro de las vecindades como un "problema social" que requiere de la acción pública reconoce antecedentes significativos. Los decretos de con-

\footnotetext{
${ }^{5}$ Nos referimos al hecho de que muchas vecindades o sus equivalentes sociales -viejos edificios de departamentos de renta congelada o muy baja- quedaron excluidas de la medida expropiatoria en colonias como la Roma norte, a las que se clasificó de "clase media", aunque también en ellas habitan en gran medida sectores populares (véase Ramos y Ortiz, 1985 y Fonhapo, 1986, "Rango salarial en el que se ubican los damnificados de la ciudad de México').
} 
gelación de rentas expedidos entre 1942 y 1948 que afectaron a alrededor de 115000 viviendas y beneficiaron a la mitad de la población, constituyen el antecedente más lejano de política urbana relacionado con las vecindades y quizás el único con un efecto masivo con consecuencias unívocamente favorables a ia conservación del uso habitacional popular en el área central de la ciudad de México. Es también el antecedente al que por lo general se suele atribuir el papel de causa fundamental del deterioro de la vivienda popular en dicha área (Durán et al., 1982). Una visión que es retomada, como veremos, en la argumentación oficial respecto de los objetivos de la expropiación de 1985.

Las políticas posteriores de renovación urbana en el área central, así como la política de grandes obras de vialidad y los cambios de usos del suelo alentados por las grandes obras emprendidas por el Estado y la empresa privada durante la gestión presidencial de José López Portillo (1976-1982) tuvieron, en proporciones variables, un saldo negativo respecto de la conservación del uso habitacional popular; éste se expresó en el desplazamiento de un sector de la población hacia la periferia de la ciudad, en parte debido a un proceso directo de expulsión y en parte como resultado de la incapacidad económica de las familias afectadas para adquirir viviendas de interés social en el área central (Coulomb, 1983: 39-45).

Los fundamentos oficiales del decreto expropiatorio y de la política habitacional dirigida a los "damnificados cuyas viviendas se encontraban en las colonias populares del centro de la ciudad", retoman el tema de la degradación de hábitat popular resultante de las rentas congeladas o muy bajas, y reconocen la insuficiencia de los programas de rehabilitación "instrumentados en el pasado", a la vez que reivindican el "arraigo" de la población y el valor "urbanístico" de la fisonomía barrial (CME, 1985: 12).

En correspondencia con esta visión del problema habitacional en el área central y atendiendo seguramente también a las repercusiones inmediatas de la medida expropiatoria, las autoridades resolvieron rectificar la lista de inmuebles afectados, haciendo públicos, a través del Regente de la ciudad, un conjunto de criterios de exclusión e inclusión que orientarían la revisión.

La versión original del decreto de expropiación incluía 5500 predios en las áreas más afectadas por el sismo. La medida fue recibida con beneplácito por las organizaciones de damnificados y con júbilo por los vecinos beneficiados. Por su parte, las organizaciones empresariales, más que oponerse frontalmente, aprovecharon para reiterar su discurso sobre el "estatismo". El Presidente de la Confederación Patronal de la República Mexicana señaló: "se trata de una decisión inquietante que puede provocar desconfianza . . . esperamos que no incremente la propiedad estatal y no signifique la estatificación de la reconstrucción", y solicitó indemnizaciones justas y oportunas para los afectados y que las nuevas vivien- 
das por edificar se enajenen en propiedad privada (Excélsior, 13-X-1985). La rectificación de la lista de inmuebles, publicada en el Diario Oficial el 21 de octubre de 1985, dio como resultado una mucha mayor concentración territorial y, aunque en conjunto implicó muchas más exclusiones que inclusiones, en ciertos casos, a través de peritajes solicitados por los vecinos, resultó en la incorporación de vecindades que habían sido omitidas en la primera versión. ${ }^{6}$

Los criterios de rectificación dados a conocer por el regente el 19 de octubre de 1985, fueron los siguientes:

1. Se excluirán. .. aquellos que no estén ubicados en las colonias populares correspondientes (sic). . . 2. Se corregirán los errores derivados de numeración oficial equivocada o duplicada. . . 3. Se excluirán las viviendas que hayan sido adquiridas por los vecinos que las habitan. . . 4. Se excluirán los predios cuyo uso sea vivienda unifamiliar. 5. Se mantendrán incluidos. . . los inmuebles baldíos o usados como bodegas no autorizadas. . . 6. Se incluirán las vecindades que por confusiones en la lista original. . . no quedaron incluidas (DDF, 1985).

En el mismo documento, procurando dar respuesta a la incertidumbre de los vecinos respecto al destino de las viviendas y a los reclamos de los propietarios, se señalaba:

. . . en su oportunidad se otorgarán las viviendas reparadas o construidas en propiedad y mediante los sistemas de crédito correspondientes. . . Por lo que se refiere a la indemnización de los propietarios de inmuebles expropiados, en fecha próxima se darán a conocer las bases correspondientes. (Ibid.)

Finalmente, subrayando la intención no "estatizante" de la medida, que como hemos visto era una preocupación de los organismos empresariales, se afirmaba: "Se ratifica que no es intención del gobierno convertirse en casero."

La distribución de predios expropiados, de acuerdo con la lista publicada el 21 de octubre se presenta en el cuadro 1. Quedaron incluidos un total de 4321 predios, distribuidos en 80 colonias localizadas en las tres delegaciones centrales del Distrito Federal, pero concentrados en 10 colonias, 6 de las cuales pertenecen a la delegación Cuauhtémoc.

Dos características de esta distribución son destacables. En primer término, que efectivamente los predios expropiados corresponden a vecindades y terrenos baldíos, es decir, que los criterios de exclusión anuncia-

${ }^{6}$ Este fue el caso en la parte sur del centro histórico, donde la Unión de Vecinos y Damnificados del Centro solicitó y obtuvo la incorporación de 32 vecindades. 


\section{CUADRO 1}

Distribución territorial de predios expropiados

\begin{tabular}{llc}
\hline Delegación & Colonia & Número de predios \\
\hline Cuauhtémoc & Buenavista & 131 \\
& Centro & 473 \\
& Doctores & 297 \\
& Guerrero & 358 \\
& Morelos & 325 \\
Gustavo A. Madero & Peralvillo & 188 \\
& Otras (15) & 424 \\
Venustíano Carranza & Valle Gómez & 137 \\
& Otras (39) & 426 \\
& Centro & 267 \\
Total & Morelos & 412 \\
& Otras (26) & 453 \\
\hline
\end{tabular}

Fuente: Diario Oficial, 21-X-85 (véase Ziccardi, 1986: 61-63).

dos se aplicaron estrictamente; pero por otro lado, un gran número de vecindades en condiciones semejantes a las comprendidas en el decreto quedaron excluidas. En segundo término, el total de las expropiaciones quedó reducido al área definida como de "colonias populares del centro de la ciudad", es decir aquella para la cual existían antecedentes de políticas de "renovación urbana", y se concentró en las colonias donde el problema inquilinario presentaba el perfil más crítico y la organización vecinal un mayor desarrollo (Guerrero, Tepito, Morelos, Doctores, Centro).

\section{Orientaciones básicas y marco institucional del PRHP.}

Transcurrido apenas un mes de la ocurrencia del sismo, la política estatal de reconstrucción habitacional contaba con una definición de la población a ser atendida que implicaba, como ya se ha señalado, la clasificación de los damnificados en tres grandes grupos a los que se aplicarían otros tantos programas de vivienda (Fonhapo, 1986: ap. 7 y Ziccardi, 1986: 44 y ss.). El PRHP, que atendería a "los damnificados cuyas viviendas se encontraban en las colonias populares del centro de la ciudad", abarcaba en principio unas 44000 familias y contaba ya con una definición de sus orientaciones básicas y de los organismos estatales que se encargarían de su ejecución.

Las orientaciones básicas quedaron definidas tanto a través de las características y funciones adjudicadas al organismo creado para ejecutarlo --Renovación Habitacional Popular (RHP), para el que se definió una 
duración limitada-, como por los informes dados a conocer por la CME el 20 de octubre de 1985 y por el DDF el 19 de ese mismo mes:

1. Adjudicar las viviendas reparadas o construidas a título oneroso, mediante un sistema de crédito y en propiedad privada a los exinquilinos.

2. Posibilitar el arraigo de los damnificados en el lugar donde habitaban antes del sismo.

3. Promover la participación popular y establecer sistemas de apoyo técnico y financiero hacia los programas de autoconstrucción y regeneración de las viviendas afectadas, así como para el funcionamiento de cooperativas de vivienda (véase CME, 1985; DDF, 1985 y 1985a).

En cuanto a los organismos estatales que participarían en el programa, la distribución de las atribuciones y funciones se dio en los términos que se presentan en el cuadro 2 .

Es importante destacar que lo novedoso en las bases políticoinstitucionales del PRHP no consiste fundamentalmente en sus orientaciones, para las cuales es posible encontrar antecedentes cuando menos en el discurso oficial, sino en el hecho de que implicaron la definición de una política social en el marco de la movilización de sus destinatarios y de una articulación notable de sus demandas, situación que contrasta significativamente con ". . . el relativo vacío en el que (habitualmente en México) se gestan las políticas públicas” (Godau, 1985: 78).

\section{Actores sociales y aparatos estatales en la ejecución del PRHP}

A diferencia de otros programas e instituciones estatales de política social de carácter permanente existentes en México, como las instituciones de seguridad social y los instrumentos de política habitacional, ${ }^{7}$ los organismos de representación patronal, así como los órganos populares de carácter corporativo incorporados al sistema oficial, ${ }^{8}$ han carecido, en el caso del PRHP, tanto de motivos como de condiciones propicias para su involucramiento directo.

En el caso de las expresiones corporativas de la empresa privada, porque el PRHP no se basa en recursos que en todo o en parte deban aportar

${ }^{7}$ Nos referimos por una parte, al Instituto Mexicano del Seguro Social y al Instituto de Seguridad y Servicios Sociales para los Trabajadores del Estado, y por otra, a los "fondos" para la vivienda: Infonavit y Fovissste y, el más reciente Fideicomiso Fondo de Habitaciones Populares (Fonhapo).

${ }^{8}$ Organizaciones sindicales por una parte (Confederación de Trabajadores Mexicanos, Congreso del Trabajo, etc.), y por otra la Confederación Nacional de Organizaciones Populares. 


\section{CUADRO 2}

Organismos estatales involucrados en el PRHP

\begin{tabular}{ll}
\hline Función & \multicolumn{1}{c}{ Organismo } \\
\hline Control del PRHP & Sedue y DDF \\
Diseño y ejecución de los proyectos de vivienda & RHP \\
$\begin{array}{l}\text { Promoción para la organización social de los damnificados } \\
\text { Instrumentación de mecanismos financieros y programas }\end{array}$ & RHP \\
$\quad$ de recuperación & Fonhapo \\
Planeación barrial, equipamiento e infraestructura & DDF y Banobras \\
\hline
\end{tabular}

Fuente: Elaborado con base en Fonhapo (1986: pto. 7.1.4.).

los empleadores y tampoco tiene implicaciones ostensibles respecto de la relación entre patrones y trabajadores. De allí que su involucramiento sólo se haya manifestado en términos de puntualizar las "desviaciones" indeseables que podría acarrear respecto de la orientación general de la política estatal. En el caso de los órganos corporativos populares, porque la población "objetivo" del PRHP constituye un conglomerado social que comparte por definición una situación común —la de damnificados-, pero que es heterogéneo en términos de su adscripción sectorial y su composición en cuanto a fuerza de trabajo, ya que está integrado por diversas categorías laborales: burócratas, obreros, trabajadores por cuenta propia, empleados en empresas privadas, etc. (Duhau, 1986a).

De allí que el conjunto de actores sociales puestos en relación por el PRHP haya resultado reducido, en lo que respecta a los de carácter primario, a los damnificados, los propietarios expropiados y los propios aparatos estatales involucrados. Mientras que en un segundo plano, es decir, en el de los actores secundarios, revisten significación ciertos partidos políticos (el PRI, sus aliados y los de oposición de izquierda), los grupos de apoyo técnico a los damnificados, las fundaciones y organismos de ayuda, la banca internacional de desarrollo y las empresas constructoras contratistas de obras.

Dado que no es posible desarrollar aquí una descripción pormenorizada de las características, acciones y recursos puestos en juego por cada uno de estos actores sociales, nos limitaremos a plantear en forma esquemática algunos aspectos que consideramos fundamentales.

\section{Los damnïficados}

En el terreno de la cuestión habitacional, una vez definidas las orientaciones generales del PRHP, la acción colectiva de los damnificados se orientó simultáneamente a presionar respecto de su pronta ejecución, a 
incidir en sus aspectos normativos y operativos, a participar en su ejecución, a exigir la ampliación de la medida expropiatoria y a desarrollar una acción de carácter autogestionario paralela a la acción gubernamental.

Aun cuando desde fines de enero de 1986 se constituyeron organizaciones de damnificados alternativas a las "uniones de vecinos y damnificados" adherentes a la CUD, constituida en octubre de 1985, tales como los Comités de Reconstrucción controlados por el PRI y el Directorio de Damnificados, controlado por el Partido Socialista de los Trabajadores (PST), no resulta problemático afirmar que han sido las agrupadas en la CUD las que, en cuanto actor colectivo, han confrontado la acción y las iniciativas gubernamentales con propuestas y demandas generadas independientemente y las que han constituido el motor de la movilización de los damnificados.

En realidad, la mayoría de los damnificados no se han organizado en forma efectiva. Afirmaciones como la de Jesús Salazar, titular de la Federación de Comités de Damnificados, respecto a que dicha organización (controlada por el PRI) "representa" a 28000 familias de damnificados, expresan una contabilidad sumamente dudosa. En todo caso, una estimación más realista ${ }^{9}$ permite situar el número de familias que siguen las orientaciones emanadas de las "uniones" agrupadas en la CUD en unas $10 \mathbf{0 0 0}$, un número significativo, si se considera que el total de familias damnificadas no excede probablemente de 80000.

En términos de una "lógica de la acción colectiva", se puede afirmar que ha sido la organización y movilización de esta minoría numéricamente significativa, la que ha otorgado sus características fundamentales a las demandas y a la acción del conglomerado heterogéneo que conforman los damnificados, ya que la progresiva concreción del PRHP (y de sus agregados como el Programa Emergente de Vivienda-fase II), se ha dado fundamentalmente en el contexto del establecimiento de negociaciones efectivas y prácticamente cotidianas entre las organizaciones que integran la CUD (alrededor de 25) y las autoridades gubernamentales involucradas en el PRHP, en el marco definido por el Estado desde fines de octubre de 1985.

\section{Los propietarios expropiados}

Así como en el caso de los damnificados tiene sentido hablar de un actor colectivo al que debe concedérsele cierta eficacia con respecto al curso seguido por la acción gubernamental, también en el caso de los propietarios expropiados sus acciones han sido eficaces, pero como resultado fun-

${ }^{9}$ Cifra resultante de las estimaciones realizadas respecto a la capacidad de movilización de la CUD y al número de familias adherentes a las principales organizaciones que la integran. 


\section{CUADRO 3}

\section{Demandas de la CUD (noviembre de 1985)}

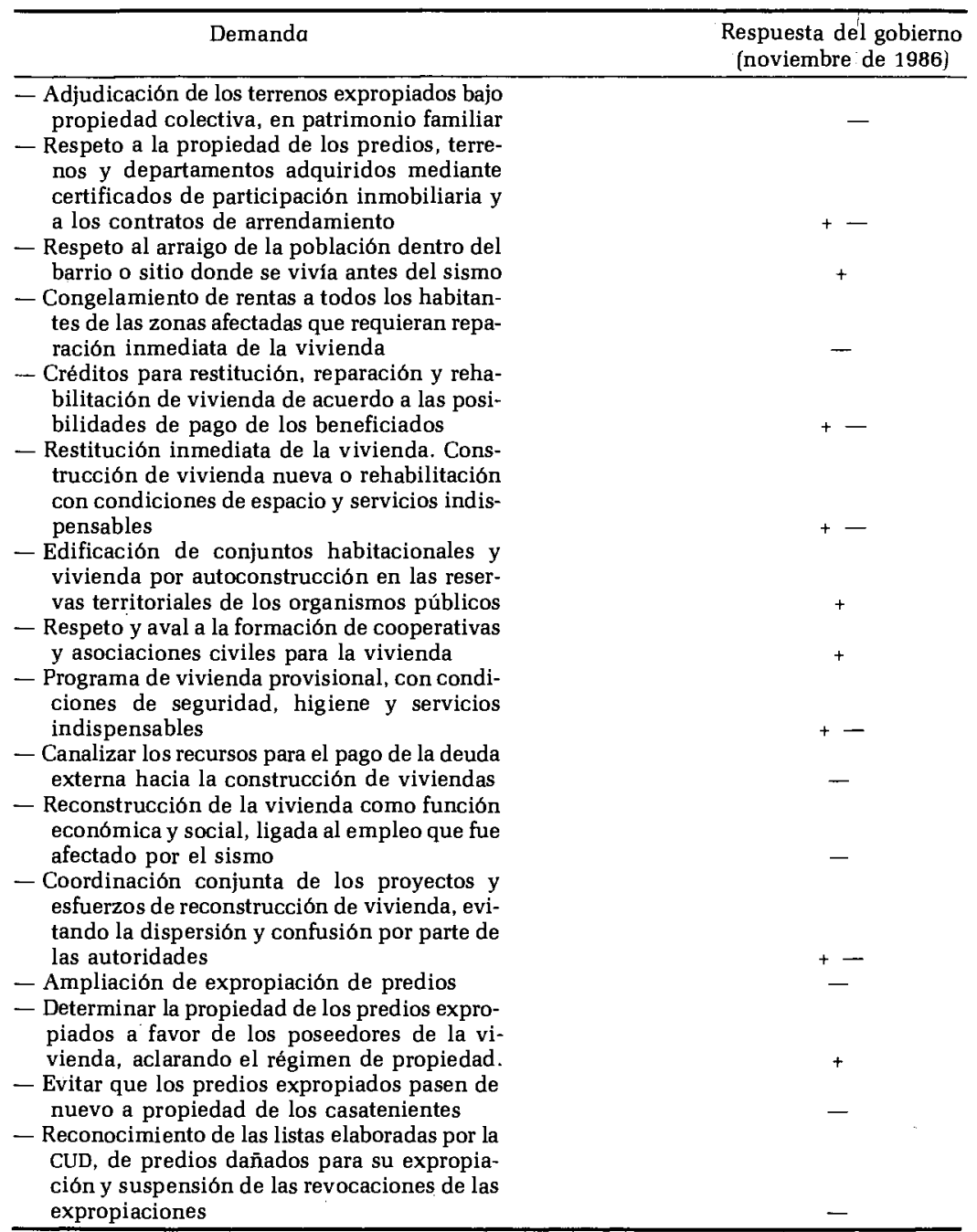

Fuente: Relatoría del Segundo Foro de Damnificados, organizado por la CuD, 9 de noviembre de 1986 (véase Massolo, 1986).

Referencias: + , incorporada por el gobierno; - rechazada; + - respuesta parcialmente positiva o de resultados ambiguos. 
damentalmente del efecto agregado de acciones emprendidas individualmente.

La reacción de los propietarios no ha sido homogénea, lo que puede explicarse tanto por el hecho de que la medida expropiatoria en sí misma podía dar lugar a interpretaciones diferentes del modo en que afectaba sus intereses, como porque éstos variaban de acuerdo con los diversos grados en que el sismo afectó a las construcciones y las características de las mismas (véase Connolly, 1985). Así, en tanto que una fracción importante optó por atenerse a la indemnización gubernamental, un número también significativo optó por anteponer los recursos legales disponibles que, en forma casuística, podían revertir la medida: solicitud de revocación ante la autoridad competente (DDF) e interposición de recurso de amparo (véase Azuela, "De inquilinos a propietarios", en este mismo volumen).

Potencialmente, todas las solicitudes de revocación denegadas pueden transformarse en recursos de amparo, y esto es al parecer lo que ha venido sucediendo en gran medida. Un número desconocido, ${ }^{10}$ pero importante de recursos de amparo ha sido resuelto en favor de los propietarios, situación que se ha convertido, como se verá más adelante, en una interferencia significativa en la ejecución del PRHP.

\section{Los aparatos estatales}

La decisión de constituir un nuevo organismo que tuviera a su cargo la ejecución del PRHP, puede ser interpretada de diferentes formas. Para Azuela (1986: 12), por ejemplo, fue la resultante del desgaste político sufrido inicialmente por las instituciones de vivienda y la consecuente necesidad de presentar una nueva imagen. Sin embargo, es necesario considerar también el hecho de que haber otorgado la responsabilidad directa del programa (posibilidad que sugiere Azuela) al Fondo de Habitaciones Populares (Fonhapo), único organismo que contaba con experiencia acumulada en programas semejantes al PRHP, hubiera significado la exclusión del gobierno de la capital —el DDF-, de un programa con enorme impacto político y social en el área central de la ciudad.

De hecho, las atribuciones conferidas a los diferentes organismos participantes y en particular a la Secretaría de Desarrollo Urbano y Ecología (Sedue) (de la cual depende Fonhapo) y al DDF, parecen haberse orientado a obtener un equilibrio en la participación de estos dos organismos. En efecto, el decreto por el que se crea RHP, señala en sus artículos octavo y decimosegundo:

La junta de gobierno estará integrada por los titulares del Departamento del Distrito Federal, quien la presidirá, y de la Secretaría de Desarro-

${ }^{10}$ No hay información oficial al respecto. 
lio Urbano y Ecología que tendrá el carácter de vicepresidente . . . El director general del organismo será designado por el titular del Poder Ejecutivo Federal, a propuesta del presidente de la junta de gobierno. .. (DDF, 1985a: 5).

Sin embargo la situación resultante de la concurrencia de la Sedue y el DDF en el PRHP, a causa entre otras cosas del papel determinante otorgado a Fonhapo (control financiero), ha sido el predominio de la primera institución.

A pesar de ello, el DDF, en su papel de "contraparte" oficial en los trámites de revocación y juicios de amparo, ha retenido el control de manejo legal y del seguimiento de los mismos. Esta situación se ha convertido, como se verá, en una fuente de dificultades para RHP, ya que a significado para dicho organismo el carecer de información oportuna respecto de la evolución de la situación legal de los predios.

Otra circunstancia generadora de inconsistencias en el desarrollo del programa, resultante también de la siempre problemática concurrencia de múltiples órganos estatales en un programa gubernamental, ha sido la dependencia de RHP de las acciones de varias secretarías y del Fonhapo, y del proceso de concertación entre las mismas, para contar con una definición de los recursos a utilizar y de los criterios y condiciones del crédito a los beneficiarios del programa (véase infra, "Los recursos para el PRHP. . .").

\section{Los actores secundarios}

Una forma posible de analizar el papel que desempeñan los actores secundarios, es considerarlos en términos de los recursos, obstáculos y apoyos que su presencia incorpora en la acción de los actores primarios. ${ }^{11}$ Desde esta perspectiva destaca, en relación con la acción colectiva desarrollada por los damnificados, el papel desempeñado por los partidos y grupos de oposición de izquierda, los grupos de apoyo técnico (en ocasiones inseparables de los primeros) y las fundaciones y organismos de ayuda.

Los partidos y grupos de oposición no han tenido una participación orgánica, es decir de carácter programático y en cuanto organizaciones políticas en el movimiento de los damnificados, pero han aportado un recurso significativo en relación con la capacidad del mismo para dar continuidad a la acción y para organizarse: básicamente, un conjunto de activistas con experiencia, en muchos casos, en la organización y gestión de organizaciones barriales y de colonos.

11 Una aproximación semejante en algunos aspectos, puede encontrarse en Pikvance (1977), en términos de la relación entre base social y fuerza social. 
Por su parte, los "grupos de apoyo técnico" - un conjunto numeroso de asociaciones civiles (véase Sedue, 1986: 75 y ss.), algunas de ellas con muchos años de experiencia en proyectos relacionados con la problemática de las colonias populares-, han proporcionado a las organizaciones de damnificados un apoyo significativo, que permitió que éstas ampliaran su capacidad para debatir y confrontar las acciones gubernamentales, para diseñar y desarrollar proyectos independientes de carácter autogestionario, para constituir cooperativas y captar y administrar los recursos proporcionados por los organismos de ayuda.

Finalmente, estos últimos, como el Consejo Ecuménico Mexicano para Ayuda a Damnificados, la Fundación de Ayuda Católica, la Cruz Roja Suiza, el Fondo de las Naciones Unidas para la Infancia, Ayuda Obrera Suiza, entre otros, a través de diversas modalidades (Duhau, 1986 y Peña Morelos, 1986), han proporcionado una masa significativa de recursos en forma de donaciones y créditos blandos, los que se canalizaron muchas veces directamente hacia las organizaciones de damnificados, proporcionándoles de ese modo las bases materiales imprescindibles para que pudieran desarrollar proyectos alternativos a los controlados por RHP.

III. Cuestiones fundamentales en la concreción del PRHP

La definición gubernamental de las orientaciones generales del PRHP y del marco institucional a través del cual sería realizado sólo proporcionaba un punto de partida; llevarlo a la práctica requería de un conjunto de definiciones mucho más específicas, así como de la instrumentación de normas y modalidades de operación inexistentes al momento de su lanzamiento. Así, la ejecución del PRHP requería la resolución de las siguientes cuestiones fundamentales: la definición de un programa operativo y de un programa de financiamiento de las acciones y de crédito a los beneficiaros; la definición de las características de los proyectos constructivos; la organización de la participación de la población abarcada por el programa; el desarrollo de un programa de vivienda provisional; el desarrolo de criterios y soluciones para los casos de los predios expropiados susceptibles de revocación, y la definición y ejecución legal del modo en que se constituiría a los exinquilinos en propietarios privados de las viviendas.

LOs recursos para el PRHP y el programa de crédito para los damnificados

Entre la decisión de otorgar a título oneroso y en propiedad privada las viviendas a los damnificados, a través de los "programas de crédito correspondientes", y su puesta en práctica, se interponía la necesidad de obtener y asignar los recursos económicos que se aplicarían y de establecer 
las condiciones del crédito a los beneficiarios. Formalmente quedaba a la Sedue, a través de Fonhapo, la responsabilidad de la instrumentación de los mecanismos financieros y de los programas de recuperación, y a la Secretaría de Hacienda y Crédito Público (SHCP) el encargo de obtener los recursos necesarios, negociando con la banca internacional uná parte de los mismos; por otra parte, RHP quedaba como interlocutor directo de los damnificados, enfrentando la necesidad de dar respuestas concretas y de comenzar la ejecución del programa. A su vez, el hecho de que sólo una parte de los recursos que se'aplicarían tuviera origen fiscal, mientras que otra debería provenir de crédito externo, limitaba el rango de opciones posibles a disposición de las autoridades.

La demora en la iniciación efectiva de las obras y la indefinición con respecto al programa de crédito, se convirtieron en un factor muy claro de desgaste político de RHP y en general de la política de reconstrucción. En febrero de 1986, el entonces titular de RHP - José Parcero López-, sólo podía anunciar lo siguiente como avances del programa:

. . . a la fecha (11-11-86.) se han atendido 900 vecindades que se encontraban en riesgo de derrumbe, se han distribuido más de cien mil piezas de madera para apuntalamiento de viviendas; se ha hecho entrega de 15 mil láminas galvanizadas y herramienta para demolición; se han derruido 120 vecindades; retirado 80 mil metros cúbicos de escombros; atendido 141 campamentos en la vía púbica, que albergan a más de 2 mil familias; construido más de mil alojamientos y entregado más de 25 mil certificados de derechos (Excélsior, 12-11-86).

Por la misma fecha, la CUD denunciaba: "la reconstrucción no ha comenzado en ninguna parte" (Excélsior, 12-I1-86), en el marco de una movilización de su base social que había venido ostentando una gran continuidad durante los meses anteriores (CIPRO, 1986: 25 y ss.).

Pero para que la reconstrucción comenzara se requerían definiciones que trascendían el ámbito de acción de RHP: obtención y asignación de los recursos presupuestales y determinación del grado de subsidio gubernamental a las viviendas. En las decisiones finalmente adoptadas tuvieron un peso significativo dos circunstancias: que gran parte de los recursos para la reconstrucción provinieran de crédito externo, y los criterios con que había venido operando Fonhapo para el financiamiento de vivienda para sectores de "bajos ingresos". (Véase Mier y Terán, 1986.)

Los recursos externos para la reconstrucción de vivienda obtenidos por el gobierno federal, han provenido de dos préstamos concedidos por el Banco Internacional de Reconstrucción y Fomento (BIRF). El primero de ellos fue concedido inicialmente para el desarrollo del Programa de Acción Concertada para el Desarrollo Urbano de la Zona Centro del Golfo e Itsmo de Tehuantepec (PACDU), en 1981, y por un monto de 164 millones de dólares, de los cuales el gobierno federal acordó con el BIRF transferir 
81.8 millones para la "reconstrucción de vivienda de bajos ingresos" (Banobras-Fonhapo, s/d). El segundo, consiste en un présamo de 400 millones de dólares formalizado el 9 de abril de 1986, destinado a la reconstrucción en el área metropolitana de la ciudad de México y del cual 132 millones se aplicarán a la "rehabilitación y reconstrucción de vivienda para sectores de bajos ingresos" y serán canalizados también a través de Fonhapo (Banobras, 1986: 1-3).

Así, de acuerdo con las cláusulas de los contratos de préstamos suscritos por el gobierno federal con el BIRF, y más allá de los motivos que llevaron a las autoridades a crear RHP en lugar de operar el programa directamente a través de Fonhapo, es esta última institución, en su calidad de "prestataria", la encargada de administrar y elaborar los programas financieros para la reconstrucción de vivienda.

Asimismo, las condiciones de los préstamos incluyen cláusulas que evidentemente han condicionado el grado de subsidio gubernamental y, con ello, las características de las viviendas, los plazos de amortización otorgados a los damnificados y la cuantía de las cuotas que éstos deberán desembolsar. Entre otras cosas el loan agreement de abril de 1986, establece:

1) Que Banobras (contratante del crédito por parte del gobierno federal), deberá adoptar las medidas que sean necesarias para que Fonhapo recupere al menos $50 \%$ de los créditos que otorgue; 2) que las tasas de interés deberán ajustarse anualmente mediante la aplicación de un factor 1.1, y 3) que las cuotas deberán ajustarse de acuerdo con la evolución del salario mínimo legal (BIRF-Banobras, 1986).

La obtención de la primera parte de los recursos provenientes del BIRF, permitió hacia febrero-marzo de 1986, definir el presupuesto de RHP para ese año, el que quedó integrado del siguiente modo:

\section{CUADRO 4}

Presupuesto de RHP para 1986

\begin{tabular}{|c|c|c|c|}
\hline Fuente & $\begin{array}{c}\text { Monto } \\
\text { (millones de pesos) }\end{array}$ & Aplicación & $\begin{array}{r}\text { Monto } \\
\text { (millones de pesos) }\end{array}$ \\
\hline Recursos fiscales & 103103.1 & $\begin{array}{l}\text { Obra civil } \\
\text { (Estudios y proyectos, } \\
\text { reforzamientos, super- } \\
\text { visión, vivienda pro- } \\
\text { visional) } \\
\text { Gasto corriente }\end{array}$ & $\begin{array}{r}70263.2 \\
4206.0\end{array}$ \\
\hline Crédito BIRF & 97409.5 & Obra civil & 97409.5 \\
\hline Total & 200512.6 & & 200512.6 \\
\hline
\end{tabular}

\footnotetext{
Fuentes: RHP (1986: 10-11) y Banobras-Fonhapo (s/d).
} 
Como se puede apreciar en el cuadro precedente, los recursos fiscales son aplicados principalmente a los gastos no recuperables, mientras que el crédito externo es aplicado a la obra civil, es decir, a la porción del gasto que se incorpora como "costo" de las viviendas que se cargará al crédito a pagar por los beneficiarios. Las condiciones y características de este último fueron planteados públicamente por el titular de RHP en mayo de 1986, en ocasión de la firma del Convenio de Concertación Democrática para la Reconstrucción.

\section{CUADRO 5}

Condiciones crediticias por tipo de programa

\begin{tabular}{|c|c|c|c|c|c|}
\hline \multirow[b]{2}{*}{ Programa } & \multicolumn{2}{|c|}{ Costo (miles) } & \multirow{2}{*}{$\begin{array}{c}\text { Enganche } \\
(\%)\end{array}$} & \multirow{2}{*}{$\begin{array}{c}\text { Afectación } \\
\text { salario mínimo } \\
(\%)\end{array}$} & \multirow{2}{*}{$\begin{array}{c}\text { Tiempo aprovechado } \\
\text { de pago } \\
\text { (años) }\end{array}$} \\
\hline & Final & Crédito & & & \\
\hline 1. Reparación menor & 1288 & 1160 & 10 & 20 & 5.5 \\
\hline 2. Rehabilitación & 2473 & 2225 & 10 & 25 & 8.0 \\
\hline 3. Reconstrucción & 3217 & 2896 & 10 & 30 & 8.5 \\
\hline
\end{tabular}

Fuente: RHP (1986: 18).

Los beneficiarios deberán abonar cuotas mensuales que oscilan entre 20 y $30 \%$ del salario mínimo legal, en las cuales se incluye el pago de tasas de interés de entre 13 y 17 por ciento anual, que se elevarán anualmente mediante la aplicación de un factor 1.1. La diferencia entre el costo "final" y el "crédito", corresponde a $10 \%$ de enganche que, a diferencia de los programas habitualmente manejados por Fonhapo, será en esta ocasión absorbido por el gobierno federal en lugar de ser pagado por los prestatarios.

De este modo, las condiciones finales del crédito resultaron de la aplicación de las condiciones normalmente aplicadas por Fonhapo en sus programas (Mier y Terán, 1986), estrechamente relacionadas con las del financiamiento internacional en que dichos programas se apoyan, y ciertas modificaciones negociadas con las organizaciones de damnificados: una leve reducción en las tasas iniciales de interés (21\% habitualmente), la eliminación del enganche y la cobertura por parte del gobierno federal de los costos adicionales en los casos de "monumentos históricos que se rehabiliten".

\section{La participación popular}

El objetivo de "propiciar la participación de la comunidad en la ejecución de las acciones, obras e inversiones que realice RHP, en especial 
de los grupos vecinales correspondientes"' (DDF, 1985: 5), asumió una situación dada de movilización social de la cual era muy problemático prescindir. Tres han sido los mecanismos fundamentales manejados por RHP para canalizar dicha movilización en términos de la ejecución del programa: la entrega de certificados personales de derechos, la constitución de comités de reconstrucción en cada vecindad, y el desarrollo de una política de "puertas abiertas" hacia los grupos y organizaciones de damnificados.

Los certificados, que se comenzaron a distribuir mucho antes de que se definieran las características concretas del PRHP, no establecen ningún derecho específico, sino que operan como una suerte de garantía ofrecida por el gobierno a los damnificados de que se respetará su carácter de beneficiarios. Por una parte, parecen haber estado destinados a reducir la incertidumbre que existía respecto del programa. Por otra, han tenido la función de acotar el grupo de las familias que serían atendidas por el PRHP. También se les ha atribuido el carácter de "instrumento de control político"'. En realidad, todo parece indicar que el propósito gubernamental de mostrar "transparencia" y eficiencia en las acciones de reconstrucción, ha redundado en que la utilización de los certificados como instrumentos de cooptación y de presión, ocupara un lugar relativamente marginal.

De acuerdo con información suministrada por el titular de RHP (Sedue, 1986: 11), para mediados de mayo de 1986 se habían entregado 38835 certificados, cifra que muestra que en rigor han funcionado como un mecanismo que ha permitido la permanencia en el programa de un número mayor de damnificados que el que hubiera resultado en caso de que su distribución se hubiera limitado a las familias que habitaban predios cuya expropiación podía considerarse definitiva.

La formación de los comités de reconstrucción como mecanismo a través del cual los vecinos se organizaron como beneficiarios y participantes en el PRHP, permite visualizar cómo al mismo tiempo que éste operó como un mecanismo gubernamental para organizar desde el Estado la movilización y el conflicto, también facilitó la organización de los damnificados más allá de los objetivos gubernamentales.

Si en general se podría afirmar que el PRHP dio como resultado que "el universo caótico y ampliamente movilizado de los damnificados se fue transformando en una ordenada fila frente a la ventanilla del subsidio oficial" (Azuela, 1986: 14), también es cierto que la organización de las vecindades para la participación en el PRHP, se constituyó en un instrumento útil para la consolidación de las organizaciones de damnificados (véase para el caso del Centro, Duhau, 1986: 6).

En cuanto a lo que hemos denominado política de "puertas abiertas", un aspecto que ha caracterizado la gestión de RHP ha sido el establecimiento del trato y la negociación directa con los grupos de vecinos, las 
organizaciones de damnificados y los grupos de apoyo, definiendo acuerdos que muchas veces se formalizaban mediante actas. Este tipo de procedimientos culminó en el Convenio de Concertación Democrática para la Reconstrucción, suscrito el 13 de mayo de 1986 por los titulares de la Sedue, el DDF y RHP, las organizaciones de damnificados, universidades, grupos técnicos de apoyo, colegios y cámaras profesionales y fundaciones y asociaciones civiles (Sedue, 1986: 75 y ss.). Si bien no debe exagerarse el significado de esta formalización del proceso de concertación, no debe ignorarse una característica importante: que implicó el reconocimiento por parte del Estado de un conjunto de organizaciones sociales ajenas al esquema corporativo de organizaciones populares controlado desde el propio Estado y desde el partido oficial.

Las claúsulas del convenio establecen los compromisos asumidos por el Estado y la sociedad civil, pero básicamente fijan en forma taxativa los alcances del PRHP, institucionalizando la participación en el mismo de los "grupos que trabajan con proyectos propios" y acotando la injerencia de RHP en tales proyectos (cláusulas quinta y sexta).

No deja de ser significativo el hecho de que Cuauhtémoc Abarca, secretario general de la CUD, señalara entre otras cosas en ocasión de la suscripción del convenio:

. . . esta fecha reviste una significación especial. . . por primera vez, en mucho tiempo, el Estado admite la pluralidad de una sociedad y reconoce la participación social . . . A nosotros nos parece muy importante que la inmensa mayoría de los planteamientos emanados de la Coordinadora única de Damnificados estén contemplados dentro del convenio (Sedue, 1986: 23 y 25).

\section{La revocación de expropiaciones}

La posibilidad, dada por la existencia de un gran número de solicitudes de revocación y juicios de amparo, de que muchos predios regresaran a manos de sus propietarios originales, se presentó desde un principio como un elemento latente de conflicto y de dificultades en la ejecución del PRHP. Como resultado de la política seguida en la distribución de certificados de derechos, existe un gran número de vecinos que cuentan con su certificado y que habitan en vecindades cuya expropiación fue revocada o es suceptible de ser revocada. Esta situación se ha dado tanto en predios donde las obras se encontraban ya muy avanzadas, como en otros donde se atrasaron considerablemente. El caso del inmueble del siglo XVIII ubicado en 5 de febrero número 68 (centro histórico), es demostrativo de lo que ha estado sucediendo. Un año después del sismo se notifícó a los vecinos que el predio había sido restituido al dueño original. La argumentación judicial se basó en que "los vecinos no demandaron el decreto de expro- 
piación" y que "la expropiación no beneficiaba a los vecinos". Por su parte, RHP no contaba con ninguna información al respecto, ni siquiera con la información de que existía un amparo (Tamayo, 1986).

De acuerdo con información extraoficial, ${ }^{12}$ en la actualidad de los 3969 predios incluidos actualmente en el PRHP, sólo 2500 están efectivamente libres de la posibilidad de revocación, y el cálculo que efectúan algunos funcionarios de RHP es que todo el programa (alrededor de 39000 viviendas), deberá realizarse en 2900 predios, es decir en $75 \%$ de los previstos inicialmente.

Tratándose de predios, como es el caso de la gran mayoría, donde los vecinos cuentan con certificado, RHP ha adoptado dos cursos de acción: negociar la compra del predio con los propietarios o reubicar a las familias involucradas en otro predio, optando por uno u otro, al parecer, según el grado de avance de las obras y la capacidad de presión de los vecinos. La adopción de la alternativa de compra del predio supone utilizar para ello recursos presupuestales que no fueron asignados con ese objetivo; la adopción de la alternativa de reubicación implica utilizar los predios baldíos (poco numerosos) y, fundamentalmente, densificar el uso en otros predios.

¿A qué atribuir este retroceso del PRHP? ¿Estamos frente a un aparato estatal mucho más inconsistente de lo que muchas veces se suele admitir y frente al hecho de que, dado un cierto marco jurídico, el poder judicial sí puede condicionar el desarrollo de una política aún en un régimen presidencialista como el mexicano; o frente a una "voluntad" estatal inconfesable de "borrar con el codo lo que se escribió con la mano"? Nos inclinamos por la primera alternativa, sin que esto signifique ignorar que la acción de los funcionarios no es ajena al modo en que las políticas gubernamentales son puestas en práctica.

\section{El condominio vecinal}

Desde el momento en que quedó definido que los exinquilinos se transformarían en propietarios de sus viviendas, se planteó tanto desde las organizaciones de damnificados como desde las instancias gubernamentales la necesidad de determinar el régimen de propiedad y administración que se establecería para las viviendas. La posición de la CUD, al igual que la de los partidos de oposición con representantes en el congreso, consistió en plantear alternativas que restringieran la incorporación de las viviendas al mercado inmobiliario. La posición gubernamental, tal como fue expresada por los diputados del partido oficial, fue establecer un régimen de propiedad privada plena que implica, como es obvio, la inexistencia de tales restricciones.

\footnotetext{
${ }^{12}$ Cifras transmitidas verbalmente por funcionarios de RHP.
} 
El debate realizado en la cámara el 16 de abril de 1986 en torno al dictamen del proyecto de decreto que establecía reformas a la Ley de Condominios en el Distrito Federal (votado favorablemente en esa fecha, instituyendo el "condominio vecinal") es ilustrativo del modo en que fue resuelto finalmente el problema.

La argumentación de los legisladores representantes de los partidos de oposición en favor de una fórmula que restringiera la circulación mercantil de las viviendas, se encuentra sintetizada en la intervención de Efraín Calvo Zarco, diputado por el Partido Revolucionario de los Trabajadores (PRT):

Ciertamente debe haber una serie de regulaciones que dificulten, aunque no imposibiliten, la transferencia de las propiedades, pues de otra forma, dejando las nuevas propiedades al libre albedrío de las fuerzas del mercado, éstas se incorporarán muy rápidamente, señores, al mercado especulativo inmobiliario, que a la larga sólo beneficiará a los grandes casatenientes urbanos, con todo tipo de maniobras de las que ya conocemos presionarán a los avecindados para arrancarles sus viviendas. . . (Congreso de la Unión, 1986: T. 72, H. 2).

El proyecto aprobado, consiste en una adición a la ley sobre "régimen de condominio de inmuebles para el Distrito Federal" con un capítulo sobre el condominio vecinal, el cual en términos positivos, simplemente establece que:

1) El condominio vecinal se podrá constituir sobre las viviendas nuevas o rehabilitadas mediante el PRHP y también sobre vecindades que sean adquiridas por los inquilinos.

2) Se eliminen los requisitos del artículo $4^{\circ}$ de la Ley Condominios que, entre otras cosas, establece la obligatoriedad de contar con lugares de estacionamiento y otra serie de instalaciones.

3) Las cooperativas de vivienda, asociaciones de inquilinos, etc., podrán determinar la forma colectiva de administrar el condominio.

4) La constitución del "condominio vecinal" requerirá de una declaratoria del Departamento del Distrito Federal a través de la cual, así como de la escritura pública, se establecerán las modalidades que adoptará. 1986).

5) No se aplicará el impuesto de sustitución de propietario. (DDF,

En resumen, el régimen "excepcional" del condominio vecinal, define por una parte la excención de ciertos requisitos que deben cumplirse dentro del régimen general de condominios y confiere al gobierno de la ciudad un instrumento de control de la nueva forma de condominio a través de la necesidad de una declaratoria que debe expedir para que pueda constituirse. 
Las alternativas planteadas por los partidos de oposición fueron fundamentalmente dos: convertir a las viviendas en patrimonio familiar, y con ello en bienes no enajenables ni embargables (PSUM); definir un régimen de copropiedad con diversas restricciones a la disposición individual de las viviendas (PRT) - entre ellas, que los vecinos sólo podrán ceder sus derechos si son autorizados por el voto favorable de las dos terceras partes de la asamblea de vecinos; prohibición del arrendamiento y pérdida de los derechos como tal del vecino que deje de habitar su vivienda por un lapso de seis meses sin causa justificada (Congreso de la Unión, 1986: T. 71, H. 2).

No cabe duda de que el gobierno optó por una alternativa que supuso evitar cualquier modalidad que implicara restringir la mercantilización de las viviendas o implicara el involucramiento del Estado en su administración. Es claro que luego de la experiencia de Tlatelolcp - un conjunto administrado por el Estado a través de la modalidad de certificados de participación inmobiliaria-, si algo no deseaban las autoridades era convertir al gobierno en "casero".

Pero si la incorporación al mercado inmobiliario de las viviendas en "condominio vecinal", es un hecho que se desprende en forma unívoca, no resultan tan claros los efectos que tal hecho tendrá. Al respecto pueden formularse dos preguntas: ¿qué grado de viabilidad práctica poseían las alternativas que tendían a la restricción de la propiedad privada?, ¿en qué medida la inexistencia de tal restricción abre el espacio para la "especulación inmobiliaria" en contra de los beneficiarios y a favor de los casatenientes?

IV. Un poco de prospectiva: reflexiones sobre los efectos sociales del PRHP

Son dos las realidades sociales a partir de las cuales parece razonable especular respecto de los efectos sociales del PRHP: la categoría social que conforman un grupo numeroso de familias pertenencientes al sector popular urbano, convertidas en propietarias de la vivienda en que habitan; y un actor colectivo, las uniones de vecinos y damnificados que, si a diferencia de la primera, no tuvieron su origen en el PRHP, en cierta medida se consolidaron y formaron un número significativo de activistas alrededor del programa de reconstrucción habitacional.

Una primera cuestión que surge y que en general ha atraído la atención de los observadores del PRHP, es la presunta incapacidad del grupo de "nuevos propietarios" para hacerse cargo del pago del crédito gubernamental. Según los datos que maneja RHP, la distribución de las familias beneficiarías por niveles de ingreso se muestra en el cuadro 6 .

Con las reservas del caso, dadas las conocidas dificultades para captar adecuadamente los ingresos de las familias, es previsible que cuando 
CUADRO 6

Familias beneficiarias del PRHP. Distribución por niveles de ingreso

\begin{tabular}{cc}
\hline $\begin{array}{l}\text { Ingreso en veces } \\
\text { el salario mínimo }\end{array}$ & Porcentaje de familias \\
\hline 0.5 & 5.3 \\
0.51 a 1.0 & 7.3 \\
1.01 a 1.5 & 19.3 \\
1.51 a 2.0 & 22.9 \\
2.01 a 2.5 & 17.8 \\
2.51 a 3.0 & 10.2 \\
3.01 a 3.5 & 6.3 \\
3.51 a 4.0 & 3.8 \\
4.0 & 6.9 \\
\hline
\end{tabular}

Fuente: RHP (1986: 33).

menos en los tres estratos inferiores, se presenten dificultades para pagar el crédito. Ahora bien, que estas dificultades vayan a derivar en la expulsión de una elevada proporción de familias no constituye una tendencia inexorable. Por una parte, la política gubernamental respecto de las familias que tengan dificultades para amortizar el crédito no es un hecho dado. La cláusula de los contratos de compra-venta que establece: que la existencia de tres mensualidades vencidas dará lugar a la rescisión del contrato, salvo que medien razones de "incapacidad", puede ser interpretada y utilizada de diversas formas. Su aplicación, por otra parte, podrá tropezar o no con la acción solidaria y organizada de los vecinos.

Otro aspecto relacionado con definiciones gubernamentales y que puede implicar un alto grado de presión sobre la capacidad de pago de los vecinos, es el relativo a los precios que el Estado fije a las tasas y servicios (predial, agua, electricidad y gas, fundamentalmente). Durante el último año, los aumentos a la electridicad y el gas han estado muy por encima del aumento promedio de precios.

Ahora bien, el posible desplazamiento de beneficiarios, no sólo debe ser relacionado con la incapacidad de pago. Existen otros factores que se presentan normalmente en torno a la vivienda de interés social, y que seguramente operarán también en este caso. Por una parte, las operaciones de traspaso motivadas por circunstancias familiares o laborales o por la existencia de alternativas habitacionales que hagan posible realizar el valor de la vivienda. Por otra, y por razones semejantes, la difusión del arrendamiento.

Si bien el contrato de compra-venta establece que las viviendas.no se podrán traspasar ni arrendar hasta que se haya cancelado la totalidad del crédito, lo probable es que tales operaciones comiencen a producirse desde un principio, tal como lo demuestra la experiencia existente en otros programas de interés social. 
Cabe preguntarse si de haberse adoptado una forma diferente de propiedad, orientada a bloquear la incorporación de las viviendas al mercado inmobiliario, los resultados hubieran sido muy distintos. Un ejemplo pertinente es el del ejido; su carácter de no enajenable no ha impedido su fraccionamiento y venta por parte de los ejidatarios para uso habitacional, dando así lugar a una de las formas fundamentales de "irregularidad" en los asentamientos populares urbanos (véase, entre otros, Azuela, et al., 1984 y Varley, 1985). Del mismo modo, no parece haber razones muy claras por las que la adopción de alguna fórmula de "propiedad social" en el caso del PRHP, no hubiera dado lugar a la aparición de una nueva modalidad de "irregularidad". Es que, más allá de la intencionalidad que pueda atribuirse a la decisión de constituir a los beneficiarios del PRHP en propietarios privados de sus viviendas, el espectro de relaciones sociales conformadas alrededor de la producción, circulación y tenencia de la vivienda en el ámbito urbano, promueve su mercantilización, la cual tiende a producirse aun cuando existan impedimentos de carácter legal para ello.

Como sea, no cabe duda de que en el caso que nos ocupa se abrirá un proceso de circulación mercantil de las viviendas, el cual llevará seguramente a que muchas de ellas se conviertan en viviendas de alquiler. ¿Autoriza esto a pensar que esta mercantilización dará lugar a un proceso de especulación inmobiliaria que operará en beneficio de los casatenientes y en contra de los nuevos propietarios? Por varias razones creemos que no. La primera, que el inquilinato en el área central de la ciudad de México no ha sido el resultado del "despojo" de viviendas, sino de un proceso de acumulación de bienes inmuebles cuya dinámica pertenece en gran medida al pasado. Lạ segunda, que es muy dudosa la existencia de un grupo de casatenientes que se encontraran a la espera de reconstituir el inquilinato con base en los condominios vecinales. La tercera, que no existen razones para suponer que las viviendas resultantes del PRHP puedan ser visualizadas como una buena inversión especulativa para el capital inmobiliario.

Lo que sí puede producirse es un proceso de sustitución de familias de los estratos más bajos por otras de estratos más elevados, y también una cierta concentración de la propiedad de las viviendas, derivada de la desigualdad económica existente entre los propios beneficiarios del programa. Seguramente, una parte de estos se convertirán en caseros.

En cuanto al actor colectivo, las uniones de vecinos y damnificados, no es arriesgado suponer que tenderán a persistir e incluso a extenderse a familias no incorporadas al pograma de reconstrucción. Los supuestos sociales para que así ocurra parecen estar dados.

Por una parte, las uniones han generado a lo largo del proceso de reconstrucción un patrimonio a administrar, conformado a través de proyectos cooperativos que en algunos casos involucran a las propias vivien- 
das y en otros a un conjunto de equipamientos colectivos: guarderías, lavanderías, comedores, talleres de capacitación, etc. Por otra parte, el proceso de politización y participación colectiva dejará entre otras cosas un saldo de activistas urbanos que tenderán a dar continuidad a la organización vecinal a partir de la problemática que deja abierta la reconstrucción habitacional: administración de los condominios vecinales, gestión y lucha por la conservación de la vivienda, demanda de equipamientos y servicios. Además, la masiva conformación de un grupo de beneficiarios dará lugar, seguramente, a la constitución del grupo de los no beneficiarios, es decir, aquellos que seguirán habitando en vecindades deterioradas e inscritos en las relaciones de inquilinato, circunstancias que los constituyen en base social potencial de las uniones de vecinos.

\section{Bibliografía}

Almanza Huesca, B. (1986), La prestación habitacional para los trabajadores sindicalizados. El caso del STIC, trabajo terminal para obtener el grado de licenciado en sociología, UAM-A, depto. de sociología.

Azuela, A. et al. (1984), "Ilegalidad y procesos sociales en cuatro colonias populares de la ciudad de México", en Revista A, vol. V, núm. 11. (1986), Sismo y expropiación en la ciudad de México. Crónica de un acto fallido, México, UAM (mimeo).

Banco Nacional de Obras y Servicios (Banobras) (1986), Contrato de apertura de crédito simple Banobras-gobierno federal, México.

Banobras/Fonhapo (s/d), Contrato de apertura de crédito simple Banobras-Fonhapo, México.

Banco Internacional de Reconstrucción y Fomento y Banobras (1986), Earthquake Rehabilitation and Reconstruction Project, Washington.

Centro de Información y Procesamiento (1986), Taller de coyuntura nacional. Suplemento especial: la reconstrucción 19-20, México, Cipro.

Comisión Metropolitana de Emergencia (1985), Informe del 19 de septiembre al 19 de octubre de 1985, México.

Congreso de la Unión (1986), Diario de Sesiones, periodo extraordinario, 16-IV-86.

Connolly, P. (1985), "El inquilinato antes y después del sismo", en El Cotidiano, año 2 , núm. 8 .

Coulomb, R. (1983), “Políticas urbanas en la ciudad central del área metropolitana en la ciudad de México", en Iztapalapa, año 4, núm. 9.

Departamento del Distrito Federal (1985), "Información a la ciudadanía de1 Distrito Federal sobre el decreto expropiatorio publicado el día 11 de octubre de 1985", Excélsior, 19-X-85.

(1985 a), "Decreto por el que se aprueba el Programa Emergente de Renovación Habitacional Popular del Distrito Federal", Diario Oficial, 12-X-86. (1985 b), "Decreto por el que se expropian por causa de utilidad pública, los inmuebles de propiedad particular que se señalan", Diario Oficial, 11-X-86. (1985 c), "Decreto por el que se expropian por causa de utilidad pública, los inmuebles de propiedad privada que se señalan", Diario Oficial, 21-X-85. (1986), "Decreto por el que se adiciona la ley sobre el régimen de propiedad en condominio de inmuebles para el Distrito Federal", Diario Oficial, 9-V-86. 
Duhau, E. (1986), "El proceso de reconstrucción de la vivienda en el centro histórico y la participación de la mujer", documento presentado en el taller "La participación social en la reconstrucción", México, Unicef-Colmex-PIEM, 5, 6 y 7 de noviembre de 1986.

(1986 a), "Les Secteurs Populaires dans le centre de la Ville de Mexico. Situation de Classe, Milieu Familial et Modalités d'insertion au Travail", en prensa, Cahiers ORSTOM.

Durán Contreras, A. (1982), La renovación urbana en la colonia Guerrero, cuaderno de investigación núm. 5, UAM-A., Depto. de Sociología.

Excélsior (1985 y 1986), ediciones que se señalan en el texto.

Godau, R. (1985), "La protección ambiental en México: sobre la conformación de una política pública", en Estudios Sociológicos, vol. 3, núm. 7.

Gough, I. (1979), The Political Economy of the Welfare State, Londres, Macmillan.

Fondo de Habitaciones Populares (Fonhapo) (1986), Las consecuencias del sismo de septiembre de 1985 en la ciudad de México, particularmente en la vivienda, México, (mimeo).

(1986 a), Programa de vivienda dañada no expropiada, México, (mimeo).

Mier y Terán, A. (1986), Ponencia presentada en el "Seminario organización popular y financiamiento para la vivienda en el marco de la crisis", México, UAM-X, noviembre de 1986.

Massolo, A. (1986), ;Que el gobierno entienda lo primero es la vivienda! La organización de los damnificados, México, IISUNAM (mimeo).

Offe, C. (1984), Contradictions of the Welfare State, Londres Hutchinson.

Peña Morelos-Casa y Ciudad (1986), La lucha de la mujer por una sociedad nueva, documento presentado en el taller "La participación social en la reconstrucción", México, Unicef-Colmex-PIEM, noviembre de 1986.

Pikvance, C. (1977), 'From 'Social Base' to 'Social Force'. Some Analitical Issues in the Study of Urban Protest", en Michael Harloe (ed.), Captive Cities, Londres, Wiley.

Ramos y Ortiz (1985), Problemática habitacional y cambio de uso del suelo. Estudio de caso: colonia Roma norte, trabajo terminal para obtener la licenciatura en sociología, UAM-A, Depto. de Sociología.

Renovación Habitacional Popular (1985), Certificado personal de derechos. (1986), Programa operativo.

Secretaría de Desarrollo Urbano y Ecología (1986), Convenio de concertación democrática para la reconstrucción, México, Sedue.

Tamayo, S. (1986), "Los damnificados. Herida en la conciencia pública", Excélsior, 22-XI-86.

Varley, A. (1986), "La zona urbana ejidal y la urbanización de la ciudad de México", Revista A, vol. II, núm. 15.

Ziccardi, A. (1986), Política de vivienda para un espacio destruido, México, IISUNAM, (mimeo). 